\title{
Potential causes of abrupt climate events: A numerical study with a three-dimensional climate model
}

\author{
H. Goosse and H. Renssen \\ Institut d'Astronomie et de Géophysique G. Lemaître, Universitécatholique de Louvain, Belgium
}

\author{
F. M. Selten, R. J. Haarsma, and J. D. Opsteegh \\ KNMI, De Bilt, The Netherlands
}

Received 26 February 2002; accepted 8 May 2002; published 18 September 2002

[1] A multi-millennia simulation performed with a threedimensional climate model under constant forcing shows abrupt climate events lasting for several centuries caused by a spontaneous transition to an infrequently visited state of the oceanic thermohaline circulation. This state is characterized by a more southern location of the main area of deep ocean convection in the North Atlantic and implies a large cooling in the mid and high latitudes of the northern hemisphere. This transition of the thermohaline circulation occurs spontaneously less than once in 5000 years in the model, but such transitions can also be triggered by a reduction of the solar irradiance. INDEX TERMS: 3309 Meteorology and Atmospheric Dynamics: Climatology (1620); 3344 Meteorology and Atmospheric Dynamics: Paleoclimatology; 4532 Oceanography: Physical: General circulation; 1650 Global Change: Solar variability. Citation: Goosse, H., H. Renssen, F. M. Selten, R. J. Haarsma, and J. D. Opsteegh, Potential causes of abrupt climate events: A numerical study with a three-dimensional climate model., Geophys. Res. Lett., 29(18), 1860, doi:10.1029/ 2002GL014993, 2002.

\section{Introduction}

[2] Abrupt events have been recorded in various archives of past climates in the North Atlantic region during the Holocene (last 11500 years) and during the previous glacial period [Dansgaard et al., 1993; van Geel et al. 1998; Bond et al., 1997]. A likely cause of those fluctuations is a perturbation of the oceanic thermohaline circulation (THC) that transports large amount of heat northward in the Atlantic. The classical paradigm states that the large THC variations are due to inputs of fresh water in the North Atlantic that perturb deep oceanic convection there [e.g., Stocker and Wright, 1991; Rahmstorf, 1994; Stocker, 2000].

[3] Nevertheless, alternative mechanisms have been proposed. It has been suggested that interactions between the Southern Ocean and the North Atlantic could also lead to large variations of the global THC [e.g., Broecker et al., 1999]. Furthermore, natural modes of variability have been proposed, invoking a slow warming of the deep ocean. This drift results in a destabilisation of the water column that leads to large oceanic flushes characterized by a huge release of oceanic heat (e.g., Weaver et al. [1993]).
[4] Recently, Hall and Stouffer [2001] have obtained a large cooling close to the southern tip of Greenland in a Coupled General Circulation model using no interannually varying forcing. This event, which is an exceptional example of the stochastic variability of their coupled system, lasts less than one century but they argue that the same processes might be responsible for longer events. Using a climate model of intermediate complexity, Ganopolski and Rahmstorf [2002] showed that stochastic fluctuations of the freshwater fluxes in the North Atlantic could induce a shift in the latitude of deep convection during glacial times, resulting in millennial-scale variability. The importance of stochastic forcing was also highlighted by Kuhlbrodt et al. [2001] in a two-box model of oceanic convection.

[5] The goal of this letter is to further study the possible causes of abrupt events. To do so, we are using a coupled three-dimensional climate model that is described in section 2. In section 3, a 13,000 year-long simulation is performed using constant forcing corresponding to pre-industrial conditions (1750 AD) in order to see if spontaneous abrupt events (i.e. not triggered by any variations of forcing) are possible in this model. In section 4, the response of the model to variations of solar irradiance is discussed. The justification of these latter experiments is the recent hypothesis that a solar-triggered reduction of the THC would be consistent with climate reconstructions during the Holocene [van Geel et al., 1998; Bond et al. 2001]. But, a mechanism justifying this hypothesis is still lacking. In this letter, we propose one.

\section{Model Description}

[6] The atmospheric component of the coupled model is ECBILT2, a global spectral quasi-geostrophic model, truncated at T21 with simple parameterizations for the diabatic heating due to radiative fluxes, the release of latent heat and the exchange of sensible heat with the surface. The model contains a full hydrological cycle which is closed over land by a bucket model for soil moisture. Synoptic variability associated with weather patterns is explicitly computed. The CLIO model is made up of a primitive equation, free-surface ocean general circulation model coupled to a thermodynamic-dynamic sea ice model. The horizontal resolution of CLIO is 3 degrees in latitude and longitude, and there are 20 vertical levels in the ocean. The coupled model includes realistic topography and bathymetry. There is no local flux correction in ECBILTCLIO. However, it is necessary to artificially reduce the precipitation by $10 \%$ over the Atlantic and by $50 \%$ over 
the Arctic basin. The corresponding water is redistributed homogeneously over the North Pacific.

\section{Description of the Spontaneous Abrupt Events}

[7] Despite the constant forcing, the model simulates two large cold events (Figure 1). The first one starts around model year 6580 and lasts about 250 years while the second one starts around model year 10950 and lasts about 100 years. The discussion in this section is focussed on the first event but similar conclusions can be drawn for the second one. During the event, the cooling is maximum at Northern Hemisphere high latitudes where temperature decreases by more than $10^{\circ} \mathrm{C}$ close to Spitzbergen (Figure 2). The cooling is felt over the whole Northern Hemisphere, while a small temperature increase is observed in the Southern Hemisphere. This perturbed state has characteristics similar to the one obtained when adding freshwater pulses in the North Atlantic in the same model [Renssen et al., 2001]. In the latter study, it has been showed that these characteristics are in good agreement with anomalies during a well-documented abrupt event observed during the early Holocene.

[8] The cold event is associated with a local shutdown of deep oceanic convection in the Greenland Sea close to Spitzbergen, which is the area where the deepest convection occurs in the model during normal years. At the same time, an increase in convection depth is observed near the Norwegian coast. As convection collapses close to Spitzbergen, the upward heat flux from the ocean to the atmosphere decreases
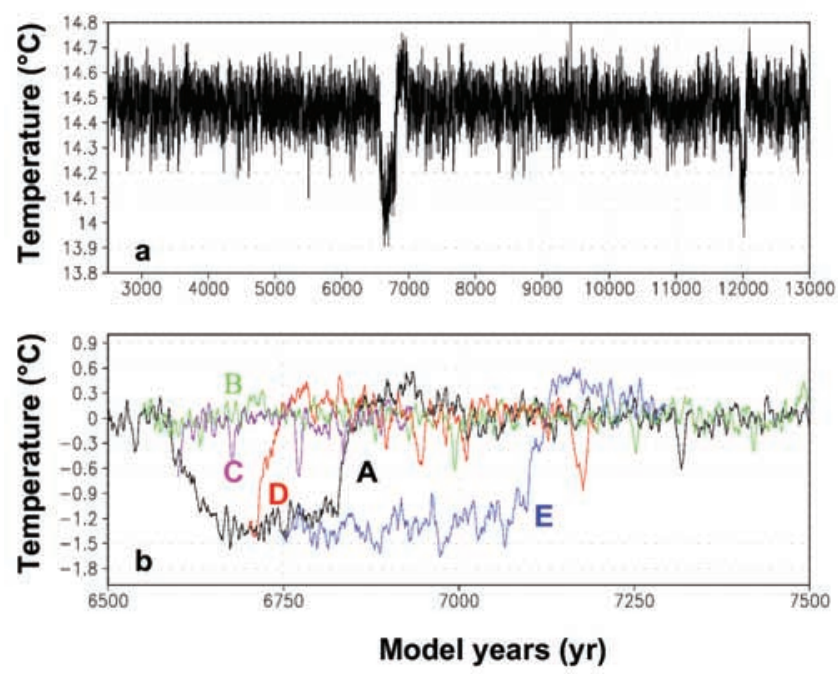

Figure 1. (a) Time series of the globally averaged annual mean surface temperature $\left({ }^{\circ} \mathrm{C}\right)$ during model years $2500-$ 13000. (b) Anomaly of the annual mean surface temperature $\left({ }^{\circ} \mathrm{C}\right)$ averaged over the regions located northward of $45^{\circ} \mathrm{N}$, in the standard experiment during model years $6500-7500$ (black, label A). The anomaly is computed relative to the years $6000-6500$ of the standard experiment. A 5-year running mean is applied to the time series. The green (label B), magenta (label C), red (label D) and blue (label E) curves correspond to experiments starting from the standard one applying a very weak perturbation at years 6550,6600 , 6700 and 6750 . The different curves can be interpreted as equally likely evolutions of the climate system.

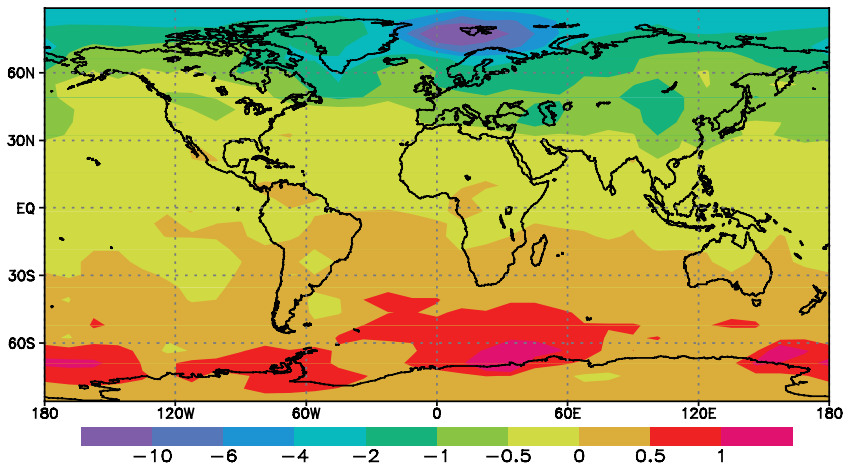

Figure 2. Anomaly of annual mean surface temperature (color bar in ${ }^{\circ} \mathrm{C}$ ) during the large event (years 6750-6800) compared to the model climatology before the event (years $6000-6500)$.

locally by more than $100 \mathrm{~W} \mathrm{~m}^{-2}$ in annual mean. This implies a strong surface cooling and results in a large increase of the ice extent.

[9] The shift in convection location induces a strong modification of the THC. The maximum of the overturning streamfunction in the Nordic Seas, decreases from $18 \mathrm{~Sv}$ to $8 \mathrm{~Sv}\left(1 \mathrm{~Sv}=10^{6} \mathrm{~m}^{3} \mathrm{~s}^{-1}\right)$. The North Atlantic Deep Water (NADW) circulation becomes shallower and the export of NADW out of the Atlantic at $30^{\circ} \mathrm{S}$ decreases by $20 \%$ (from 15 to $12 \mathrm{~Sv}$ ), while the inflow of Antarctic bottom water close to the bottom increases from 4 to $8 \mathrm{~Sv}$. As the main convective site is located more southward, warmer NADW is produced. Those changes imply a reduction of heat transported northward by the Atlantic Ocean at all latitudes. This decrease amounts to $0.1410^{15} \mathrm{~W}$ at the equator $(24 \%)$, to $0.1910^{15} \mathrm{~W}$ at $50^{\circ} \mathrm{N}(32 \%)$, and to $0.1710^{15} \mathrm{~W}$ at $70^{\circ} \mathrm{N}(63 \%)$.

[10] At the beginning of the cold event, the geopotential height anomalies at $800 \mathrm{hp}$ over the Nordic Seas strongly increase whereas geopotential height decreases over Greenland. We have shown in a previous study [Goosse et al., 2002] that such anomalies take part in a feedback loop responsible for decadal climate variability in the model. The atmospheric anomalies induce a cooling at Northern Hemisphere high latitudes. In addition, anomalous northerly winds induce a strong increase in southward ice export out of the Barents Sea. This ice is transported directly to the convection site close to Spitzbergen. There, it damps the vertical mixing since sea ice reduces oceanic buoyancy losses to the atmosphere and brings freshwater to the convection area.

[11] By chance, around model year 6580, the anomalies associated with those processes are able to trigger a convection shift. To confirm that the transition indeed occurred accidentally, a simulation of the coupled model has been restarted from the state obtained in model year 6550 , i.e. 30 years before the start of the event. During the first time step of this simulation, the freshwater, heat and momentum fluxes at the atmosphere-ocean interface have been modified in order to perturb the system slightly (Figure 1B, curve B). This small perturbation changes the evolution of the atmospheric circulation and no large event occurs during the 2000 years of this simulation. 
[12] During the event, two positive feedbacks tend to maintain the system in this state. The first one is the classical convection feedback [e.g., Lenderink and Haarsma, 1996] that can be summarized as follows: when convection is active at one location, it brings warm and salty deep water to the surface. The heat is rapidly transferred to the cold atmosphere in winter, but the salt remains. This increases local density and thus preconditions the water column for convection at the same location the following years. Secondly, the surface cooling and the increase of ice extent in the modified state tend to induce a further increase of geopotential height in the Nordic Seas. This reinforces the initial atmospheric circulation anomaly and thus also contributes to the stabilization of the climate system in the state without convection close to Spitzbergen.

[13] Nevertheless, the modified state appears only metastable and after a few hundred years the system shifts back to its normal state. This transition is also linked with high frequency climate variability. Therefore, the duration of the event is not predictable since slight perturbations of the climate system can increase or decrease the duration of the event by hundreds of years compared to the standard simulation (Figure 1B, curves C, D, E). These variations of the length of the event also indicate that the shift back to the normal state is not caused by a slow, long-term erosion of the stratification associated with the formation of warmer NADW. At the beginning of the cold event, the temperature increases in the North Atlantic between 500 and $3000 \mathrm{~m}$. This reduces the density at depth and the stability of the water column. But, after the initial adjustment that lasts about 100 years, deep-water temperature in the North Atlantic is nearly stable.

[14] It must also be stressed that the simulated THC is not close to a bifurcation point, a state that has been shown to be unstable or highly variable [Knutti and Stocker, 2002]. We have performed an additional experiment in which the system is perturbed by a freshwater flux increasing slowly at a rate of $0.1 \mathrm{~Sv}$ per 1000 years in the North Atlantic, following the procedure described in Stocker and Wright [1991] or Rahmstorf and Ganopolski [1999]. No serious change of the model THC occurs before the perturbation reaches $0.13 \mathrm{~Sv}$ and a collapse of the circulation, with no deep convection in the North Atlantic, occurs not before a perturbation of $0.23 \mathrm{~Sv}$. These values are in the upper range of the results obtained with other models [e.g., Rahmstorf and Ganopolski, 1999]. During this experiment, it was not possible to obtain a stable state characterized by a maximum of convection depth close to Norway and no convection southward of Spitzbergen.

\section{Response to a Decrease of Solar Irradiance}

[15] Starting form the control experiment, we have performed three idealized sensitivity experiments in which the solar irradiance at the top of the atmosphere has been abruptly reduced by $5 \mathrm{~W} \mathrm{~m}^{-2}(0.4 \%)$. This lower value is then kept constant for the entire experiment. The reduction of solar irradiance corresponds to a forcing at the surface of about $1 \mathrm{~W}$ $\mathrm{m}^{-2}$ and results in a global mean surface cooling of the order of $0.5^{\circ} \mathrm{C}$. Although the radiative perturbation is in the range of estimated solar irradiance variations during the last millenium [e.g., Bard et al., 2000], the purpose of these sensi-

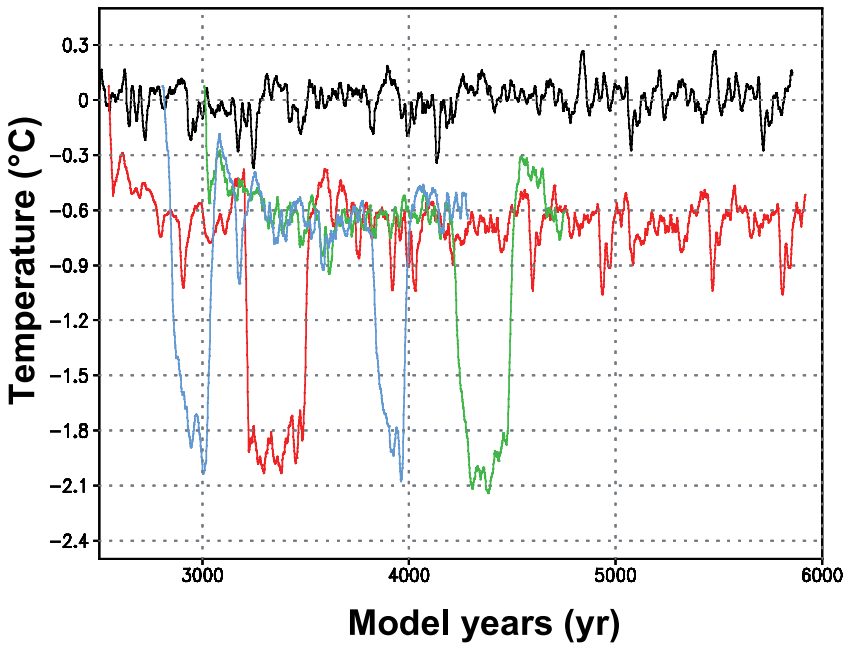

Figure 3. Anomaly of the annual mean surface temperature $\left({ }^{\circ} \mathrm{C}\right)$ averaged over the regions located northward of $45^{\circ} \mathrm{N}$. Starting from different years of the standard experiment (black), the blue, red, and green curves correspond to three experiments in which we have reduced solar irradiance by 5 $\mathrm{W} \mathrm{m}{ }^{-2}$. All anomalies are computed relative to the years $6000-6500$ of the standard experiment. A 25-year running mean is applied to the time series.

tivity experiments is not to study precisely the response of the system to any observed variations of solar forcing. The goal is to illustrate potential mechanisms responsible for an amplification of the response of the climate system. The forcing is thus idealized here for an easy analysis of the results.

[16] In the three experiments that differ only in their initial conditions (Figure 3), the reduction of solar irradiance triggers an adjustment process which manifests itself as at least one large cooling event due to a local convection shutdown. In the first experiment, an event occurs after less than 50 years while in the other two, it happens 820 and 1150 years after the change in the solar forcing. The duration and anomaly patterns of these events are similar to the spontaneous events in the control experiment.

[17] The adjustment process proceeds as follows. After the decrease in solar irradiance, the first hundred meters of the North Atlantic cool in a few decades. This implies an increase in the water density. Close to Spitzbergen, the density increase is larger at depth than at the surface. Two factors play a role. First, as the surface temperature is close to freezing point in winter, a large cooling is not possible while at depth the ocean is warmer and cooling can thus be larger. Second, the thermal expansion coefficient is about two times smaller at the surface compared to $500 \mathrm{~m}$ because of the lower temperature. This density change implies a stronger vertical stratification close to Spitzbergen that preconditions the water column for a local shut down of convection. As a consequence, abrupt events can be triggered by decadal-scale climate variability more easily.

[18] When convection shuts down, density strongly decreases at depth because of freshening and warming there. After the event, density increases again but it does not reach the values obtained before the event. Instead, the density profile returns to a state close to the state simulated in the standard experiment. As density at depth remains lower, the 
probability of a local convection shutdown and thus of a large cooling event should become very low after this initial adjustment, as in the standard experiment.

[19] Additional idealized experiments in which the solar irradiance has been reduced abruptly by $3 \mathrm{~W} \mathrm{~m}^{-2}$ or the $\mathrm{CO}_{2}$ concentration decreased by $50 \mathrm{ppm}$ confirm the hypothesis that a cooling could trigger events in our model. Besides, a moderate warming is less efficient in triggering large events. Starting from a cold equilibrium state obtained by using a value of the solar constant reduced by $5 \mathrm{~W} \mathrm{~m}^{-2}$, we have increased abruptly the solar irradiance to its normal value in three 1200-year long experiments. In none of the experiments, a large event was simulated.

\section{Conclusions}

[20] We have shown that a spontaneous transition between two states of the THC is possible in the standard version of our three-dimensional atmosphere-ice-ocean model using constant pre-industrial forcing. In the normal state, deep convection occurs north of $75^{\circ} \mathrm{N}$, while in the disturbed state, which appears less stable, the main site of convection is located more southward. The occurrence and duration of the events presented here are not predictable with precision since the beginning and the end of the event are linked with the high frequency climate variability. The duration of the simulated events ranges from 70 years to more than 500 years. This results underlines the influence of high frequency forcing for convection transition [Kuhlbrodt et al., 2001; Hall and Stouffer, 2001; Renssen et al., 2001; Knutti and Stocker, 2002; Ganopolski and Rahmstorf, 2002].

[21] The probability of a spontaneous transition is very low in the model, but an adequate forcing can trigger one. It has been demonstrated previously that this can be achieved by a freshwater perturbation [Rahmstorf, 1994, Lenderink and Haarsma, 1996]. Here, we have shown that an externally induced cooling caused by a reduction of solar forcing can trigger a transition as an adjustment of the ocean to the forcing.

[22] Whatever the cause of the event (i.e., spontaneous, induced by a freshwater forcing or a reduction of solar irradiance), the spatial pattern of the anomalies during the event, the magnitude and the duration of the changes are quite similar. As these anomalies are in good agreement with reconstructions based on paleoclimate records [Renssen et al., 2001], this makes the search of the cause of a particular observed event even more difficult than previously believed.

[23] Previous modeling studies have underlined that stratospheric processes, associated with changes in ozone concentration, could amplify the climate response to the variations of solar irradiance [e.g., Haigh, 1996]. Our model does not include an interactive representation of stratospheric ozone and is not able to simulate such processes. On the other hand, our results provide complementary amplification mechanism associated with a solar-triggered reduction of the THC.

[24] In our sensitivity experiments, the cold events occur between 30 and 1150 years after the abrupt reduction of solar irradiance. Although the uncertainties in the dating leaves room for lags, there is no observational evidence of a delay of several centuries between solar forcing and climate response. A hypothesis is that the model simulates the right mechanism but, in some simulations, is not able to reproduce the right time scale. This problem could be due to the model itself. Imposing an idealized forcing could also play a role. This will be investigated in the near future.

[25] Acknowledgments. We wish to thank M. Crucifix., T. Fichefet, A. Porson, T. Stocker, and two anonymous referees for their constructive criticism. This study was supported by the Second Multiannual Scientific Support Plan for a Sustainable Development Policy (Federal Office for Scientific, Technical, and Cultural Affairs, Contract EV/10/9A) and the Concerted Research Action 097/02-208 (French Community of Belgium).

\section{References}

Bard, E., G. Raisbeck, F. You, and J. Jouzel, Solar irradiance during the last 1200 years based on cosmogenic nuclides, Tellus, 52B, 985-992, 2000.

Bond, G., W. Showers, M. Cheseby, R. Lotti, P. Almasi, P. deMenocal, P. Priore, H. Cullen, I. Hadjas, and G. Bonani, A pervasive millennialscale cycle in North Atlantic Holocene and glacial climates, Science, 278, 1257-1266, 1997.

Bond, G., B. Kromer, J. Beer, R. Muscheler, M. N. Evans, W. Showers, S. Hoffmann, R. Lotti-Bond, I. Hajdas, and G. Bonani, Persistent solar influence on North Atlantic climate during the Holocene, Science, 294, 2130-2133, 2001

Broecker, W. S., S. Sutherland, and T. H. Peng, A possible 20th-century slowdown of Southern Ocean deep water formation, Science, 286, $1132-$ $1135,1999$.

Dansgaard, W., S. J. Johnsen, H. B. Clausen, D. Dahl-Jensen, N. S. Gundestrup, C. U. Hammer, C. S. Hvidberg, J. P. Steffensen, A. E. Sveinbjornsdottir, J. Jouzel, and G. Bond, Evidence for general instability of past climate from a 250-kyr record, Nature, 364, 218-220, 1993.

Ganopolski, A., and S. Rahmstorf, Abrupt glacial climate changes due to stochastic resonance, Phys. Rev. Let., 88, 038501, 2002.

Goosse, H., F. M. Selten, R. J. Haarsma, and J. D. Opsteegh, A mechanism of decadal variability of the sea-ice volume in the Northern Hemisphere, Clim. Dyn., (doi: 10.1007/s00382-001-0209-5) 2002.

Haigh, J. D., The impact of solar variability on climate, Science, 272, $981-$ 984, 1996.

Hall, A., and R. J. Stouffer, An abrupt climate event in a coupled oceanatmosphere simulation without external forcing, Nature, 409, 171-174, 2001.

Knutti, R., and T. F. Stocker, Limited predictability of the future thermohaline circulation close to an instability threshold, J. Clim., 15, 179-186, 2002.

Kuhlbrodt, T., S. Titz, U. Feudel, and S. Rahmstorf, A simple model of seasonal open ocean convection. Part II: Labrador Sea stability and stochastic forcing, Ocean Dyn., 52, 36-49, 2001.

Lenderink, G., and R. J. Haarsma, Modeling convective transitions in the presence of sea ice, Phys. Ocean., 26, 1448-1467, 1996.

Rahmstorf, S., Rapid climate transitions in a coupled ocean-atmosphere model, Nature, 372, 82-85, 1994.

Rahmstorf, S., and A. Ganopolski, Simple theoretical model may explain apparent climate instability, J. Clim., 12, 1349-1352, 1999.

Renssen, H., H. Goosse, T. Fichefet, and J.-M. Campin, The 8.2 kyr BP event simulated by a global atmosphere-sea-ice-ocean model, Geophys. Res. Let., 28, 1567-1570, 2001.

Stocker, T. F., and D. G. Wright, Rapid transitions of the ocean's deep circulation induced by changes in surface fluxes, Nature, 351, 729732,1991

Stocker, T. F., Past and future reorganizations in the climate system, Quatern. Sc. Rev., 19, 301-319, 2000.

Van Geel, B., J. var der Plicht, M. R. Kilian, E. R. Klaver, J. H. M. Kouwenberg, H. Renssen, I. Reynaud-Farrera, and H. T. Waterbolk, The sharp rise of $\Delta^{14} \mathrm{C} c a .800 \mathrm{cal} \mathrm{BC}$ : Possible causes, related climatic teleconnections and the impact on human environments, Radiocarbon, 40, 535-550, 1998 .

Weaver, A. J., J. Marotzke, P. F. Cummins, and E. S. Sarachik, Stability and variability of the thermohaline circulation, J. Phys. Ocean., 23, 39-60, 1993.

H. Goosse and H. Renssen, Institut d'Astronomie et de Géophysique G. Lemaître, Chemin du Cyclotron, 2, B-1348 Louvain-la-Neuve, Belgium. (hgs@astr.ucl.ac.be)

F. M. Selten, R. J. Haarsma, and J. D. Opsteegh, KNMI, P.O. Box 201,3730, AE De Bilt, The Netherlands. 